See discussions, stats, and author profiles for this publication at: https://www.researchgate.net/publication/272374840

\title{
Assessment of shear capacity of adhesive anchors for structures using neural network based model
}

Article in Materials and Structures · January 2015

Dol: 10.1617/511527-015-0558-x

CITATIONS

4 authors, including:

Esra Mete Güneyisi

Gaziantep University

61 PUBLICATIONS 365 CITATIONS

SEE PROFILE

atoing 7

Kasım Mermerdaş

Harran University

56 PUBLICATIONS 848 CITATIONS

SEE PROFILE

Some of the authors of this publication are also working on these related projects:

Msc Co-author View project

Beton Ankrajlarının Statik ve Tekararlı Yükler Altındaki Davranışlarının İncelenmesi View project
107 PUBLICATIONS 2,542 CITATIONS

SEE PROFILE 


\title{
Assessment of shear capacity of adhesive anchors for structures using neural network based model
}

\author{
Esra Mete Güneyisi • Mehmet Gesoğlu • \\ Erhan Güneyisi $\cdot$ Kasım Mermerdaş
}

Received: 17 July 2014 / Accepted: 3 February 2015 / Published online: 8 February 2015

(C) RILEM 2015

\begin{abstract}
In this study, an artificial neural network (NN) based explicit formulation for predicting the edge breakout shear capacity of single adhesive anchors post-installed into concrete member was proposed. To this aim, a comprehensive experimental database of 98 specimens tested in shear was used to train and test $\mathrm{NN}$ model as well as to assess the accuracy of the existing equations given by American Concrete Institute and prestressed/precast concrete Institute. Moreover, the proposed NN model was compared with another existing model which had been derived from gene expression programming by the authors in a previous study. The prediction parameters utilized for derivation of the model were anchor diameter, type of anchor, edge distance, embedment depth, clear clearance of the anchor, type of chemical adhesive, method of injection of the chemical, and compressive strength of the concrete. The proposed model yielded correlation coefficients of 0.983 and 0.984 for training and testing data sets, respectively. It was found that the predictions obtained from $\mathrm{NN}$ agreed well with experimental observations, yielding approximately $5 \%$ mean absolute percent error.
\end{abstract}

E. M. Güneyisi ( $)$ · M. Gesoğlu · E. Güneyisi Civil Engineering Department, Gaziantep University, 27310 Gaziantep, Turkey

e-mail: eguneyisi@gantep.edu.tr

K. Mermerdaş

Civil Engineering Department, Hasan Kaloyoncu

University, Gaziantep, Turkey
Moreover, in comparison to the existing models, the proposed NN model had all of the predicted values in $\pm 20 \%$ error bands while the others estimated up to $\% 160$ error.

Keywords Adhesive anchors - Anchor bolt . Modeling · Post-installed fastener $\cdot$ Shear capacity

\section{Introduction}

In the design of adhesive anchors embedded in concrete, the knowledge of load carrying capacity in tension and/or shear is of prime importance on the performance assessment of the structural system. Postinstalled anchors are embedded in holes that are drilled into available structural concrete member. By this way, the applied loads onto the secondary structure is transferred by means of the anchoring system onto the primary system through the frictional forces occurring between the sides of the holes and the anchor wedges, sleeves or other mechanical locking devices attached. Type of anchor system affects the mechanism of load transfer. Post-installed anchors can be classified in two categories based on the load transfer mechanism: (a) mechanical or expansion anchors which transfer load through friction and (b) adhesive or bonded anchors which rely on adhesion between the anchor and adhesive or between the adhesive and concrete to transfer the loads [1-12]. 
During service life of the anchored connection of a structure tensile loads or shear loads or a combination of both shear and tension may be subjected to the anchor [6]. Several failure mechanism occurs as a result of ultimate loading such as: steel failure, pullout failure, splitting failure, and concrete cone failure (in case of short embedment or low strength concrete) due to tensile loading conditions on the anchor system. However, failures due to exceeding shear capacity are failure of the anchor, steel concrete pry-out fracture, and concrete rupture, etc. [1].

Analytical modeling of shear capacity of the anchor bolts might be considered as a relatively new subject in the available technical literature. For example, $\mathrm{Xu}$ et al. [13] presented a numerical simulation of anchor bolt pullout in plain concrete by a heterogeneous model. They modeled the heterogeneity of the concrete by randomly assigning strength and elastic modulus to the elements according to Weibull's distribution. They stated that the numerical results agreed well with their experimental investigations. Lee et al. [11] carried out an experimental study on shear behavior of headed anchors with large diameters and deep embedments. The study was basically depended on the comparison of the experimental shear capacities to those calculated from available relations given by ACI 349 and ACI 318 design codes. It was pointed out that the existing methods gave less shear capacities for the specimens under investigation. Another study by Bickel and Shaik [12] compared the prediction capabilities of the models codified in PCI Design Handbook and CCD model from ACI 318-02 for shear capacity of the headed and adhesive anchors. It was reported that PCI Design Handbook method and CCD method, with proper adjustments, can be utilized for predicting the shear capacities of adhesive anchors with similar accuracy.

The prediction models use several parameters for estimating the shear capacity of the adhesive anchors. All of the shear capacity prediction models include compressive strength of the concrete and edge distance parallel to the loading direction. Besides, the models proposed by ACI 349 and ACI 318 (CCD model) also contain anchor diameter and embedment depths. However, type of anchor bolt (rebar or threaded rod), type of chemical adhesive, method of injection and clear clearance of the drilled hole are not taken into account when computing the shear or pullout capacities of the post-installed anchors. For example, the hole diameter is typically 10 or 25 percent larger than the inserted anchor bolt or bar diameter [3]. Therefore, the effect of clear clearance can be considered as a factor influencing the mechanical behavior of anchor.

In recent years, there has been growing interest in utilization of artificial intelligence based soft-computing techniques for modeling of complicated engineering problems [14-18]. Due to higher accuracy and simplicity of implementation, those techniques have been become alternative to conventional numerical methods. For example, Mermerdaş et al. [18] pointed out that gene-expression programming (GEP) based mathematical formulation of drying shrinkage of concretes yielded more accurate results than that of multiple linear regression. Moreover, being one of the most commonly used soft-computing tool, artificial neural networks (NNs) have been known to have exceptional performance as regression tools, particularly when used for pattern recognition and function estimation. They are highly nonlinear, and can capture complex interactions among input/output variables in a system without any prior knowledge about the nature of these interactions [19].

The studies regarding soft-computing based modeling of mechanical properties of adhesive anchors are very limited [20, 21]. Sakla and Ashour [20] utilized NN to illustrate the relation between tensile capacity of adhesive anchors and the components of the anchor system such as chemical resin type, anchor type, grout/injection type, etc. They stated that $\mathrm{NN}$ is a useful technique for predicting the tensile capacity of adhesive anchors based on the comparison of predicted and experimental results. In the study of Gesoğlu and Güneyisi [21], the prediction models to estimate the pullout capacity of adhesive anchors through soft-computing methods of NN and GEP were developed. They reported that the prediction capability of the proposed models and the CCD method were increased for deeper embedment depth and larger diameter anchors. However, both of the aforementioned studies dealt with the tensile capacity of post-installed adhesive anchors embedded in uncracked concrete.

Modeling of load carrying capacity of single anchors located near a concrete edge under shear by NN was presented by Alqedra and Ashour [22]. They compared the results obtained from $\mathrm{NN}$ with the ones obtained from CCD method. They reported that the 
accuracy of approximation using the CCD method is comparable to that obtained from the trained artificial neural network. However, they did not present an explicit mathematical expression of the NN model. Hence, the study showed that NN could be benefited for modeling purpose. In a more recent study of the authors of this paper [23], the explicit formulation of shear capacity of single anchor embedded in uncracked concrete was presented. It was illustrated that using gene expression modeling (GEP) yielded better prediction performance than the available ones given in design guidelines [12, 24-30].

The aforementioned facts that NN has better prediction performance than GEP and there has not yet been an explicit formulation derived from $\mathrm{NN}$ method motivated the authors to use this soft computing technique for explicit formulation. Therefore, the aim of this study is to propose a handful tool for prediction of the edge breakout shear capacity of post-installed anchors with a reasonable degree of accuracy. For the purpose of explicit formulations of the shear capacity of single adhesive anchors, the worldwide database compiled by the ACI Committee 355 was utilized. Totally, 98 adhesive single anchor tests were selected regarding shear load testing in uncracked concrete. A softcomputing technique, namely artificial neural network (NN) was employed for developing the analytical model. Additionally, the proposed model was compared with the existing GEP model presented in the previous study of the authors [23] and other models specified in ACI 318 [28], ACI 349 [25-27], and Prestressed/Precast Concrete Institute (PCI) $[12,30]$ as well as modified CCD method proposed by Hoffman [24].

\section{Predictive formulations of shear capacity of single anchor}

Several methods to evaluate the concrete edge breakout strength of anchor bolts under shear loading have been proposed in the technical literature as given in equations presented in Table 1 [12, 24-30]. The formulas presented in Table 1 use the following units: $\mathrm{V}_{\mathrm{u}}$ is the ultimate shear capacity of an adhesive anchor in uncracked concrete ( $\mathrm{N}$ for the Eqs. in SI unit \& $\mathrm{lb}$ for the Eqs. in U.S. customary units); $f_{\mathrm{c}}$ ' is concrete compressive strength (MPa for the Eqs. in SI unit \& Psi for the Eqs. in U.S. customary units) to be verified using cylinders; $f_{\mathrm{cc}}$ is concrete compressive strength (MPa) to be verified using $200 \mathrm{~mm}$ cubes; $h_{\mathrm{ef}}$ is embedment depth $(\mathrm{mm}) ; d_{\mathrm{o}}$ is diameter of anchor $(\mathrm{mm}$ for the Eqs. in SI unit \& in. for the Eqs. in U.S. customary units); $l$ is load bearing length of anchor ( $\mathrm{mm}$ for the Eqs. in SI unit \& in. for the Eqs. in U.S. customary units); and $c_{1}$ is anchor edge distance ( $\mathrm{mm}$ for the Eqs. in SI unit \& in. for the Eqs. in U.S. customary units).

As seen in Table 1, the American Concrete Institute (ACI) and Prestressed/Precast Concrete Institute (PCI) proposed different formulas that are used in the shear design of single adhesive anchor embedded in concrete structural members. The ACI shear resistance formula assumes the concrete failure surface to be a semicone of height equal to edge distance and a contact inclination angle of $45^{\circ}$ with respect to the contact edge [25]. The shear resistance of anchor bolt is calculated on the basis of the tensile strength of the concrete acting over the projected area of the semicone surface. According to ACI 349-97 [26], the design shear strength is given by a formula in U.S.

Table 1 Available formulations for shear capacity of single adhesive anchor in uncracked concrete

\begin{tabular}{lll}
\hline Equation no. & Design guide & General expression \\
\hline 1 & ACI 349-97 $[25,26]^{\mathrm{a}}$ & $V_{\mathrm{U}}=0.522 c_{1}^{2} \sqrt{f_{\mathrm{c}}^{\prime}}$ \\
2 & ACI 349-06 [27] & $V_{\mathrm{U}}=9.8\left(l / d_{0}\right)^{0.2} \sqrt{d_{0}} \sqrt{f_{\mathrm{c}}^{\prime}} c_{1}^{1.5}$ \\
3 & Concrete Capacity Design (CCD method) in $[28,29]^{\mathrm{a}}$ & $V_{\mathrm{U}}=1.1\left(l / d_{0}\right)^{0.2} \sqrt{d_{0}} \sqrt{f_{\mathrm{cc}}^{\prime}} c_{1}^{1.5}$ \\
4 & Modified CCD method by Hofmann et al. $[24]^{\mathrm{a}}$ & $V_{\mathrm{U}}=3 d_{0}^{0.1\left(h_{\mathrm{ef}} / c_{1}\right)} h_{\mathrm{ef}}^{0.1\left(d_{0} / c_{1}\right)^{0.2}} \sqrt{f_{c c}^{\prime}} c_{1}^{1.5}$ \\
5 & PCI method $[12,30]^{\mathrm{a}}$ & $V_{\mathrm{U}}=5.2 c_{1}^{1.5} \sqrt{f_{\mathrm{c}}^{\prime}}$ \\
\hline
\end{tabular}

\footnotetext{
a In SI units

b In U.S. customary units
} 
Fig. 1 Representative postinstalled single adhesive anchor subjected to shear loading

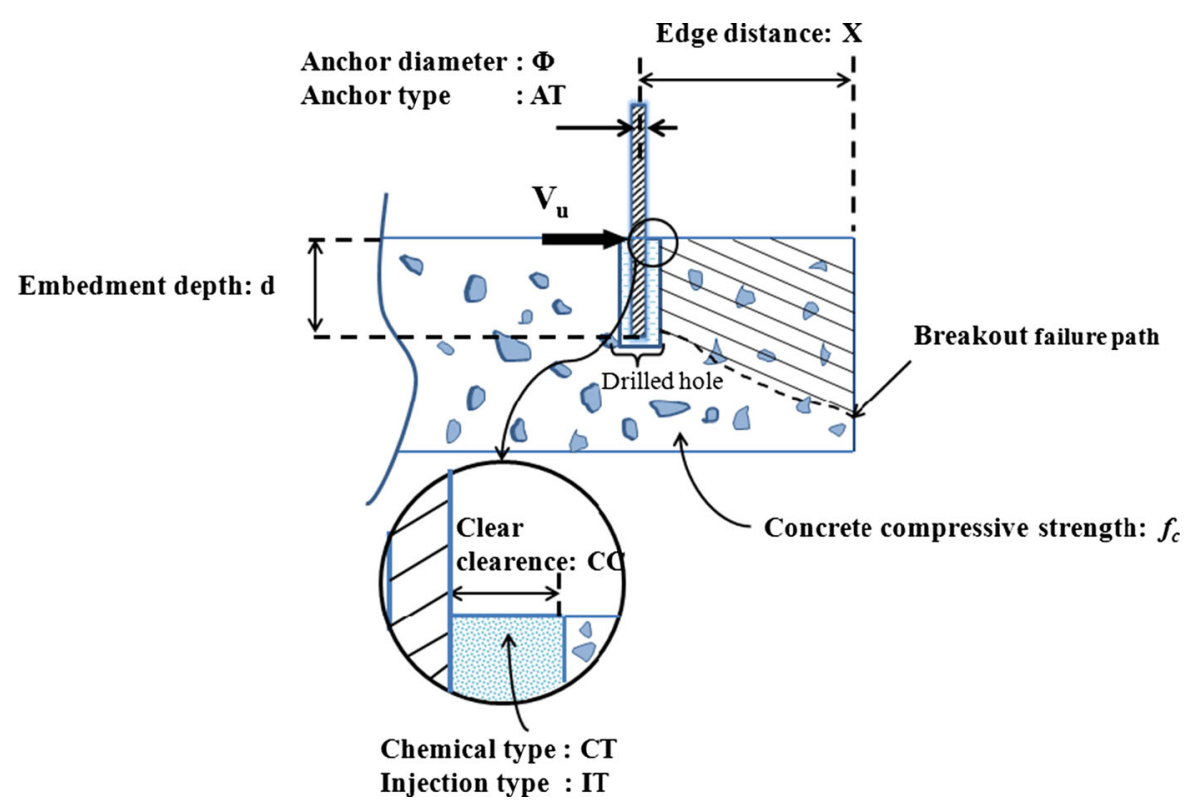

customary units, however, Ueda et al. [25] presented the same relation in SI units (Eq. 1 in Table 1). The concrete capacity design method is based on K-method developed by University of Stuttgart (Germany) in the late 1980s [12, 29]. For ACI 349-06 [27], the value of $k=7$ was valid for cracked concrete while the tests selected herein were performed in uncracked concrete. Assuming a ratio of uncracked to cracked strength of 1.4 , a value $k=9.8(k=7 \times 1.4)$ was utilized for the evaluation of predicted capacities [11]. In ACI 349-06 [27], edge breakout shear capacity of bolt was presented in U.S. customary units (Eq. 2 in Table 1). The models based on concrete capacity design (CCD) [28, 29] and modified CCD [24] were given as Eqs. 3 and 4 in Table 1, respectively. The capacity of a single anchor in uncracked structural member under shear loading toward the free edge is also described in Precast/Prestressed Concrete Institute (PCI) Design Handbook (fifth edition) [30] (Eq. 5 in Table 1).

\section{Description of the database used for derivation of the models}

When loaded in shear, adhesive anchor's adhesive layer bears on the concrete. With enough force this will cause the edge of the concrete to break out [12].
Figure 1 shows a typical edge breakout failure of a single adhesive anchor graphically. Moreover, Fig. 1 represents the significant parameters that are considered in modeling of shear capacity. The models given in the design codes basically depend on the compressive strength of the concrete and edge distance. In some of these formulas, the embedment depth of the anchor and diameter of the bolt are also taken into account as presented in above. However, clearance distance (see Fig. 1), type of the anchor and adhesive related properties such as type of adhesive used and method of injection has not yet been considered in the formulation of shear capacity of the anchor.

The adhesive anchor database containing 98 experimental data samples compiled by ACI committee 355 was utilized to construct NN prediction model. The following parameters were considered as input variables: anchor diameter, type of anchor (threaded bar or rebar), edge distance, embedment depth, clear clearance of the anchor, type of chemical adhesive (epoxy or unsaturated polyester), method of injection of the chemical (glass capsule or cartridge injection), and compressive strength of the concrete. Moreover, the experimental results of shear capacity of the anchors were considered as the dependent output variable. The data set was randomly divided into two groups (Table 2). One of the sub-data set was used as "Train set" while the other one was employed as 


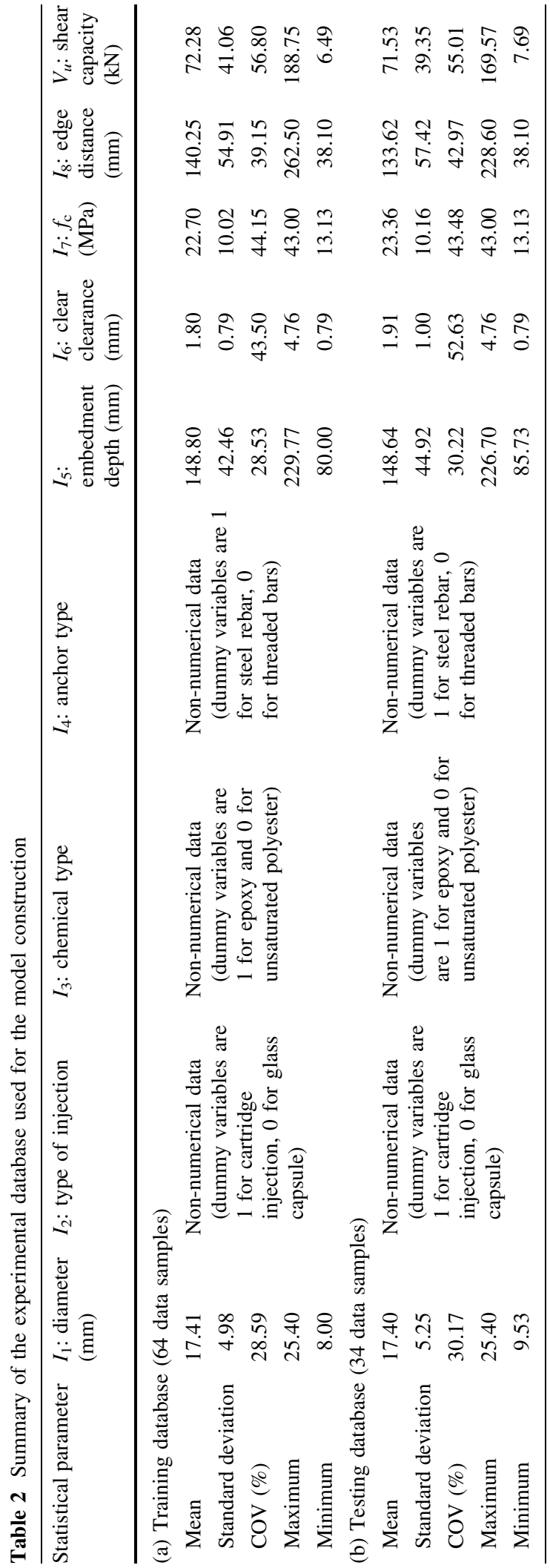

"Test set". More details regarding each data sample can be found in the study of the authors [23].

For clarity sake, in the next Sections, where it is discussed the comparison between the experimental and predicted shear capacity, the effectiveness of the correlation is evaluated by means of the correlation coefficient " $R$ " (Eq. 6), which describes the fit of the models' output variable approximation curve to the actual test data output variable curve. Higher $R$ coefficients indicate a model with better output approximation capability.

$R=\frac{\sum\left(m_{i}-m^{\prime}\right)\left(p_{i}-p^{\prime}\right)}{\sqrt{\sum\left(m_{i}-m^{\prime}\right)^{2} \sum\left(p_{i}-p^{\prime}\right)^{2}}}$,

where $m^{\prime}$ and $p^{\prime}$ are mean values of measured $\left(m_{\mathrm{i}}\right)$ and predicted $\left(p_{\mathrm{i}}\right)$ values, respectively.

\section{A brief overview of artificial neural networks (NNs)}

Soft-computing is described as a collection of methodologies that aim to exploit the tolerance for imprecision and uncertainty to achieve tractability, robustness, and low solution cost. Fuzzy logic, neurocomputing, and probabilistic reasoning are the main components of soft-computing [31]. Softcomputing has a significant role in wide variety of fields of application. The key model for softcomputing is the human mind. The fuzzy logic, genetic algorithm, genetic programming, and neural network can be accepted as the main techniques of soft-computing.

An artificial neural network (NN) is an information processing paradigm that is inspired by the way biological nervous systems such as the brain, process information. The main element of this paradigm is the novel structure of the information processing system. It is composed of a large number of highly interconnected processing elements (neurons) working unitedly to solve specific problems. NNs, like people, learn by example. An NN is configured for a specific application, such as pattern recognition, data classification, or prediction through a learning process. Learning in biological systems involves adjustments to the synaptic connections that exist between the neurons [32]. 
The training of NNs by back propagation have three stages [33]: (i) the feed forward of the input training pattern, (ii) the calculation and back propagation of the associated error, and (iii) the adjustment of the weights. This process can be used with a number of different optimization strategies. The error between the output of the network and the target value is propagated backward during the backward pass and used to update the weights of the previous layers [3436].

In this study, neural network fitting tool (nftool) provided as a soft-computing tool in Matlab V.R2012a was used to develop neural network modeling. In fitting problems, a neural network may be used to map between a data set of numeric inputs and a set of numeric targets. The nftool helps creating and training a network, and evaluating its performance through mean square error and regression analysis.

A two-layer feed-forward network with sigmoid hidden neurons and linear output neurons are utilized in nftool. It can fit multi-dimensional mapping problems arbitrarily well, given consistent data and enough neurons in its hidden layer. The network was trained with Levenberg-Marquardt back propagation learning algorithm. The toolbox utilized in this study provides the creation of a neural network to generalize nonlinear relationships between example inputs and outputs. However, the Levenberg-Marquardt algorithm does not handle bound constraints.

An artificial neuron consists of three main components, namely weights, bias, and an activation function. Each neuron receives inputs $I_{1}, I_{2}, \ldots, I_{n}$ attached with a weight $w_{i}$ which shows the connection strength for that input for each connection. Each input is then multiplied by the corresponding weight of the neuron connection. A bias can be defined as a type of connection weight with a constant nonzero value added to the summation of weighted inputs, as given in Eq. 7. Generalized algebraic matrix operation was also given in Eq. 8 to clarify the mathematical operations in an artificial neuron. It is worthy to note that the term biases come to handle the randomness of observations. In experiments, such randomness is not there, so requirement of biases does not come. This is problem due to toolbox, where we cannot eliminate the biases term.

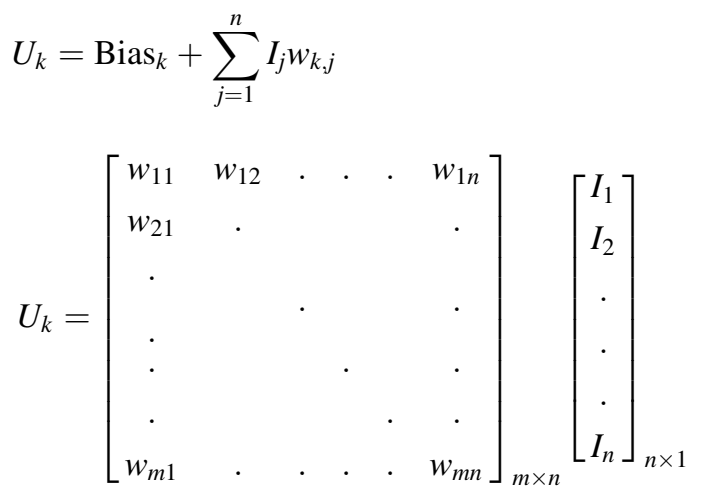

$$
+\left[\begin{array}{c}
\text { Bias }_{1} \\
\text { Bias }_{2} \\
\cdot \\
\cdot \\
\text { Bias }_{m}
\end{array}\right]_{m \times 1}=\left[\begin{array}{c}
U_{1} \\
U_{2} \\
\cdot \\
\cdot \\
\cdot \\
U_{m}
\end{array}\right]_{m \times 1} .
$$

Since nftool uses the normalized values in the range of $[-1,1]$, the input parameters were normalized by means of Eq. 9 in order to get the prediction results after execution of the training process of the $\mathrm{NN}$. Moreover, the obtained results are also in the normalized form. Therefore, considering the Eq. 9 and the normalization coefficients $a$ and $b$ for outputs, denormalization process is applied and the results are monitored.

$\beta_{\text {normalized }}=a \beta+b$,

where $\beta$ is the actual input parameter or output values given in Table 2. $\beta_{\text {normalized }}$ is the normalized value of input parameters or outputs ranging between $[-1,1]$. $a$ and $b$ are normalization coefficients given in the following equations (Eqs. 10-11).

$a=\frac{2}{\beta_{\max }-\beta_{\min }}$,

$b=-\frac{\beta_{\max }+\beta_{\min }}{\beta_{\max }-\beta_{\min }}$,

where $\beta_{\max }$ and $\beta_{\min }$ are the maximum and minimum actual values of either inputs or outputs. The normalization coefficients for both input and output variables are given in Table 3. 
Table 3 Normalization coefficients

\begin{tabular}{llllll}
\hline Variables & Parameters & $\beta_{\max }$ & $\beta_{\min }$ & $a$ & $b$ \\
\hline Input variable & Anchor diameter: $\Phi(\mathrm{mm})$ & 25.4 & 8 & 0.114942529 & -1.91954023 \\
& Injection type: IT & 1 & 0 & 2 & -1 \\
& Chemical type: $\mathrm{CT}$ & 1 & 0 & 2 & -1 \\
& Anchor type: AT & 1 & 0 & 2 & -1 \\
& Embedment depth: $d(\mathrm{~mm})$ & 229.8 & 80 & 0.013353952 & -2.068316147 \\
& Clear clearance: $\mathrm{CC}(\mathrm{mm})$ & 4.7625 & 0.79375 & 0.503937008 & -1.4 \\
& Compressive strength of concrete: $f_{\mathrm{c}}$ (MPa) & 43 & 13.12545 & 0.066946615 & -1.878704449 \\
& Edge distance: $X(\mathrm{~mm})$ & 262.5 & 38.1 & 0.008912656 & -1.339572193 \\
Output variable & Shear capacity: $V_{\mathrm{u}}(\mathrm{kN})$ & 6.49 & 188.75 & -0.010973462 & 1.071217775 \\
\hline
\end{tabular}

Fig. 2 Architecture of NN model

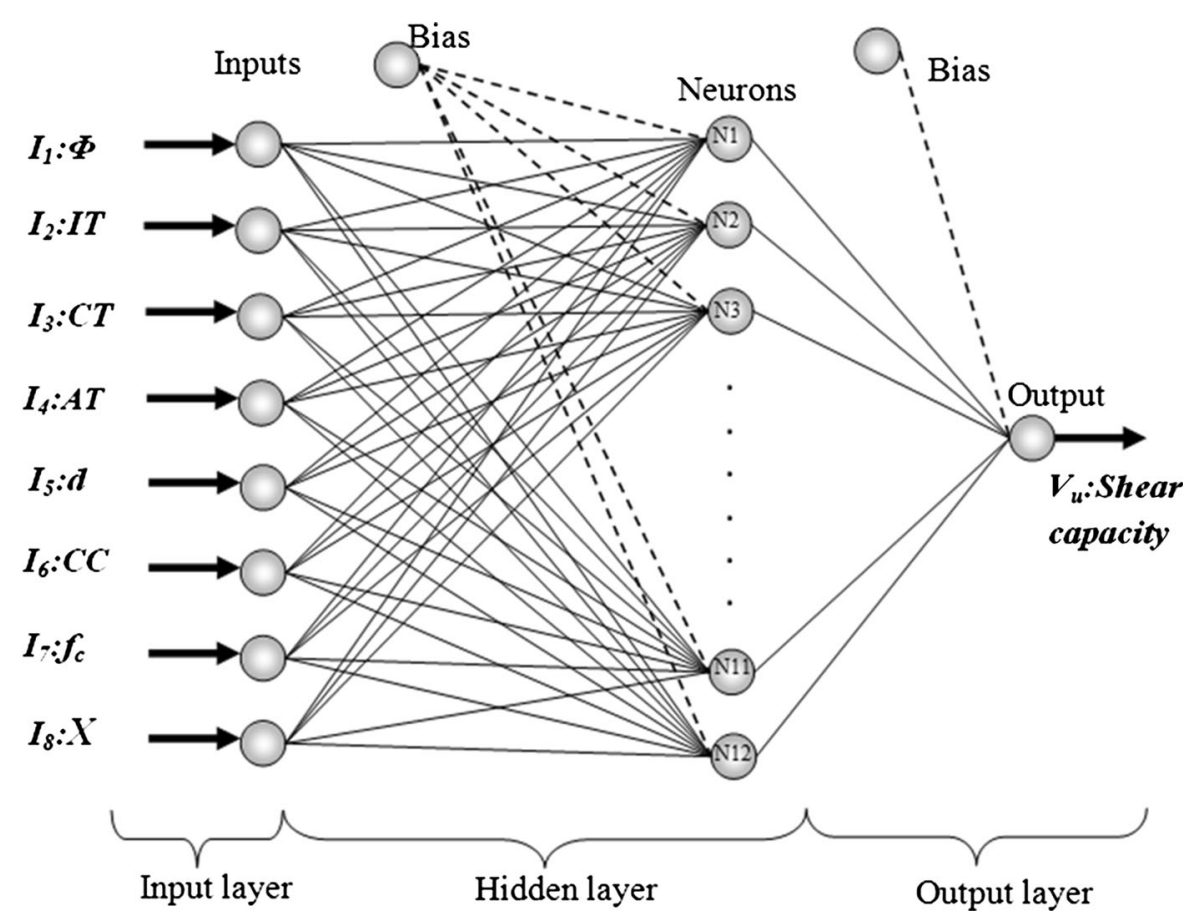

\section{Proposed NN model and its performance}

In order to develop the NN model, a 8-5-1 NN architecture, as shown in Fig. 2, was used. Figure 2 shows that there are 8 nodes in the input layer, corresponding to 8 factors from $I_{1}$ to $I_{8}, 12$ nodes in the hidden layer, and one in the output layer corresponding to the shear capacity of the single adhesive anchors. The symbols representing the input parameters $I_{1}$ to $I_{8}$ are also defined in Fig. 1. It should be taken into account that all variables were normalized to a range of $[-1,1]$ before being introduced to the NN. Therefore, one must enter the normalized values in the mathematical operations given for $\mathrm{NN}$ model. The proposed NN model is given in Eq. 12 together with corresponding mathematical operations in hidden layer (Eqs. 13-14). In Eq. 12, $V_{\mathrm{u}}$ is the ultimate shear capacity of adhesive anchor in uncracked concrete $(\mathrm{kN})$, Bias $_{\text {output layer }}=-0.26761$ and $f(x)$ (Hyperbolic tangent) is the activation function given in Eq. 14. It should also be noted that the final result obtained from Eq. 12 is also in the normalized form which needs to be de-normalized according to Eq. 9 and normalization coefficients given in Table 3 . 


$$
V_{\mathrm{u}}=-0.26761+\left[\begin{array}{c}
1.2418 \\
1.4579 \\
-1.1797 \\
-0.7718 \\
-0.2919 \\
-1.4166 \\
0.5120 \\
0.6930 \\
1.0257 \\
1.6466 \\
-0.8257 \\
1.2988
\end{array}\right]^{T}\left[\begin{array}{c}
f\left(U_{1}\right) \\
f\left(U_{2}\right) \\
f\left(U_{3}\right) \\
f\left(U_{4}\right) \\
f\left(U_{5}\right) \\
f\left(U_{6}\right) \\
f\left(U_{7}\right) \\
f\left(U_{8}\right) \\
f\left(U_{9}\right) \\
f\left(U_{10}\right) \\
f\left(U_{11}\right) \\
f\left(U_{12}\right)
\end{array}\right],
$$

where $U_{k}$ given in matrix operations in Eq. 13 and $f(x)$ is the activation function in Eq. 14. where $\Phi$ is the Anchor diameter (mm); IT is the injection type (1 for cartridge injection, 0 for glass capsule); CT is the Chemical type ( 1 for epoxy and 0 for unsaturated polyester); AT is the type of anchor (1 for steel rebar, 0 for threaded bars); $d$ is the embedment depth (mm); CC is the clear clearance $(\mathrm{mm}), f_{\mathrm{c}}$ is the concrete compressive strength (MPa), and $X$ is the edge distance $(\mathrm{mm})$.

$f(x)=\frac{2}{1-\mathrm{e}^{-2 x}}-1$.

The obtained results from the NN model are also plotted in Fig. 3 yielding 0.983 and 0.984 correlation coefficients for training and testing data sets, respectively. As observed from Fig. 3, the predicted results had very close trend to the actual ones for both of

$$
\begin{aligned}
& {\left[\begin{array}{l}
U_{1} \\
U_{2} \\
U_{3} \\
U_{4} \\
U_{5} \\
U_{6} \\
U_{7} \\
U_{8} \\
U_{9} \\
U_{10} \\
U_{11} \\
U_{12}
\end{array}\right]=\left[\begin{array}{cccccccc}
-0.47 & -0.9449 & 1.1098 & 0.2653 & -0.8465 & -0.4521 & -0.5515 & -0.0809 \\
-0.5853 & -0.1776 & -1.2637 & -1.4672 & 0.4513 & 0.0302 & 1.463 & 1.0222 \\
-1.3299 & -0.3033 & 0.2166 & -1.2382 & -0.2369 & 0.6796 & -2.4515 & 0.6946 \\
1.9056 & 1.1666 & -0.5142 & 0.4814 & 0.2086 & -0.5978 & 0.989 & 1.4602 \\
0.4666 & -0.3093 & -0.5135 & 0.2699 & 1.1421 & 0.2635 & 1.5717 & -0.7578 \\
0.0416 & -1.7541 & -0.684 & -0.1319 & -0.9474 & -0.6994 & -0.864 & -0.4473 \\
-0.6306 & 0.7531 & -0.8011 & 1.1391 & 0.4748 & -0.8408 & -0.186 & -0.1151 \\
-0.046 & -0.1931 & -0.7283 & 1.5152 & 1.3387 & 1.3752 & -1.3792 & -0.6054 \\
1.7385 & 0.6681 & 0.2405 & 1.0548 & 0.035 & 0.083 & 0.7423 & -0.5862 \\
0.2983 & -1.5484 & 0.9065 & -1.2437 & -0.2261 & 0.2784 & -2.6039 & 0.059 \\
-0.7023 & 0.5626 & 0.3841 & -1.1372 & 0.4828 & -1.188 & 0.4252 & -0.6915 \\
-1.1589 & 0.9695 & -0.5927 & -0.6157 & 1.0862 & -0.1989 & -1.0251 & 0.994
\end{array}\right]} \\
& \times\left[\begin{array}{c}
\phi \\
\mathrm{IT} \\
\mathrm{CT} \\
\mathrm{AT} \\
d \\
\mathrm{CC} \\
f_{\mathrm{c}} \\
X
\end{array}\right]+\left[\begin{array}{c}
-2.2899 \\
0.9021 \\
1.1364 \\
-0.2237 \\
0.3559 \\
0.5826 \\
-0.4028 \\
-0.4177 \\
1.09 \\
-1.4663 \\
-1.8643 \\
1.9262
\end{array}\right]
\end{aligned}
$$


Fig. 3 Prediction performance of the proposed $\mathrm{NN}$ model for training and testing database

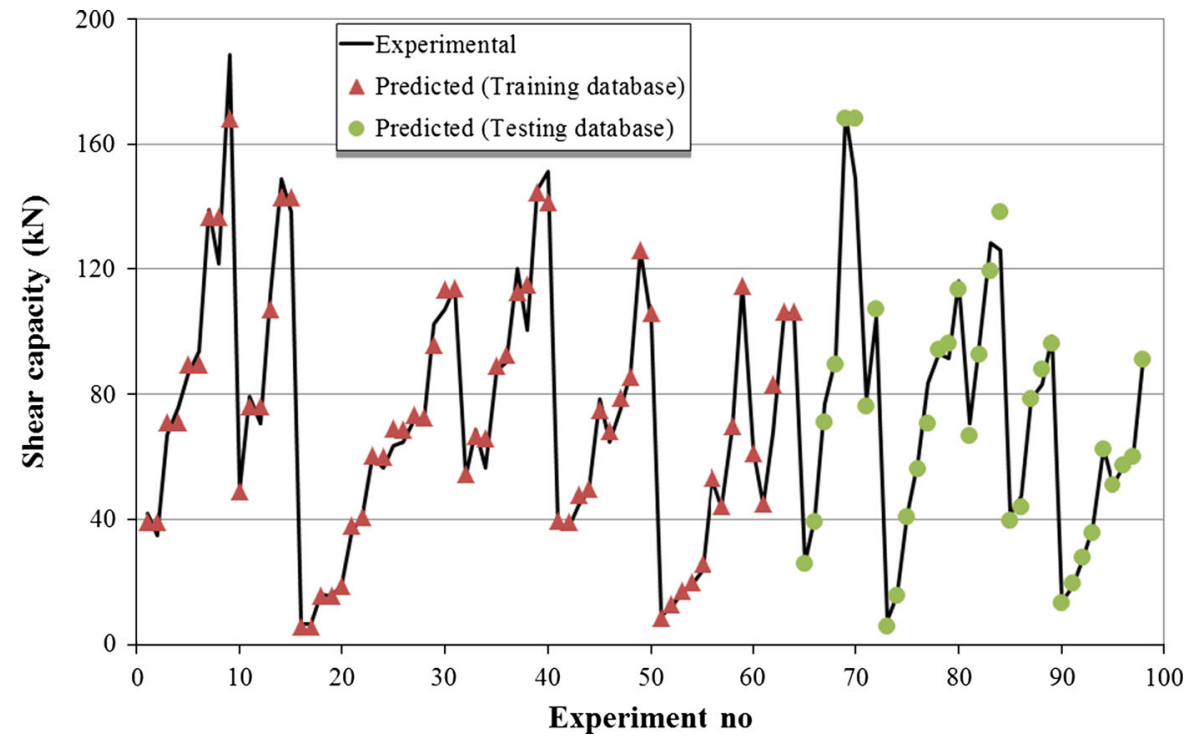

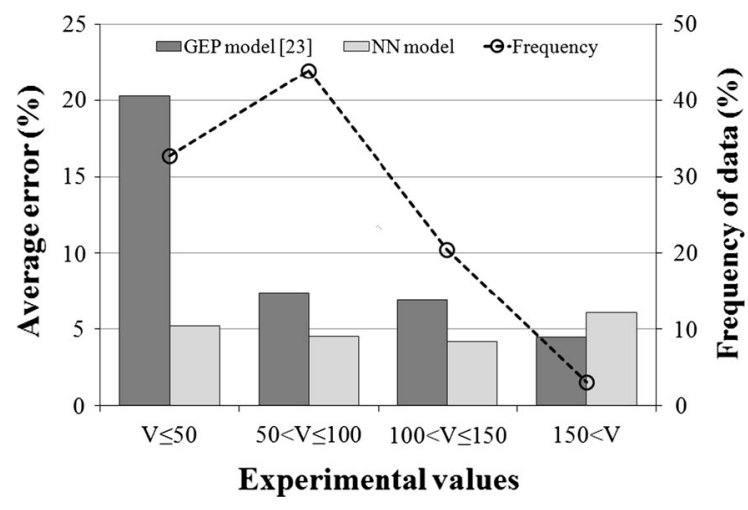

Fig. 4 Graphical presentation of the absolute errors of NN model versus GEP model [23] with respect to the actual shear values

training and testing data sets. Moreover, the percent errors obtained from the prediction values and the frequency of the experimental data in the specified intervals are presented in Fig. 4. Figure 4 also illustrates the comparison of the errors of the previously proposed GEP model [23]. Observing the figure, it was found out that for the low levels of experimental shear capacity values up to $50 \mathrm{kN}$, the average error between predicted and the actual values were relatively high
(20\%) for GEP model while relatively lower errors were obtained for the proposed NN model. The level of error for the proposed $\mathrm{NN}$ model is fluctuating around $5 \%$. However, only for small portion of the whole data set (about $3 \%$ ) were GEP model [23] yielded lower error.

In order to observe the distribution of the predicted data obtained from the proposed model and from the existing ones presented in Table 1 and GEP model [23], Fig. 5 was plotted. As seen from the figure that the NN model demonstrated the closest scatter of the data around bisector line while the others yielded either lower or higher distribution of the data.

For further examination of the prediction performance of the proposed model, normalized results calculated by dividing predicted result by actual ones are given in Fig. 6. According to the normalized values $\left(V_{\text {predicted }} / V_{\text {experimental }}\right.$, being the $V_{\text {predicted }}$ the calculated value of shear capacity and $V_{\text {experimental }}$ that experimentally measured), the perfect estimation performance is equal to 1 . It was evident from Fig. 6 that the closest trend in variation of the normalized values around 1 was observed for the NN model. Conversely, the other models revealed large fluctuations diverging from the actual 
Fig. 5 Experimental versus predicted anchor shear capacities for different models

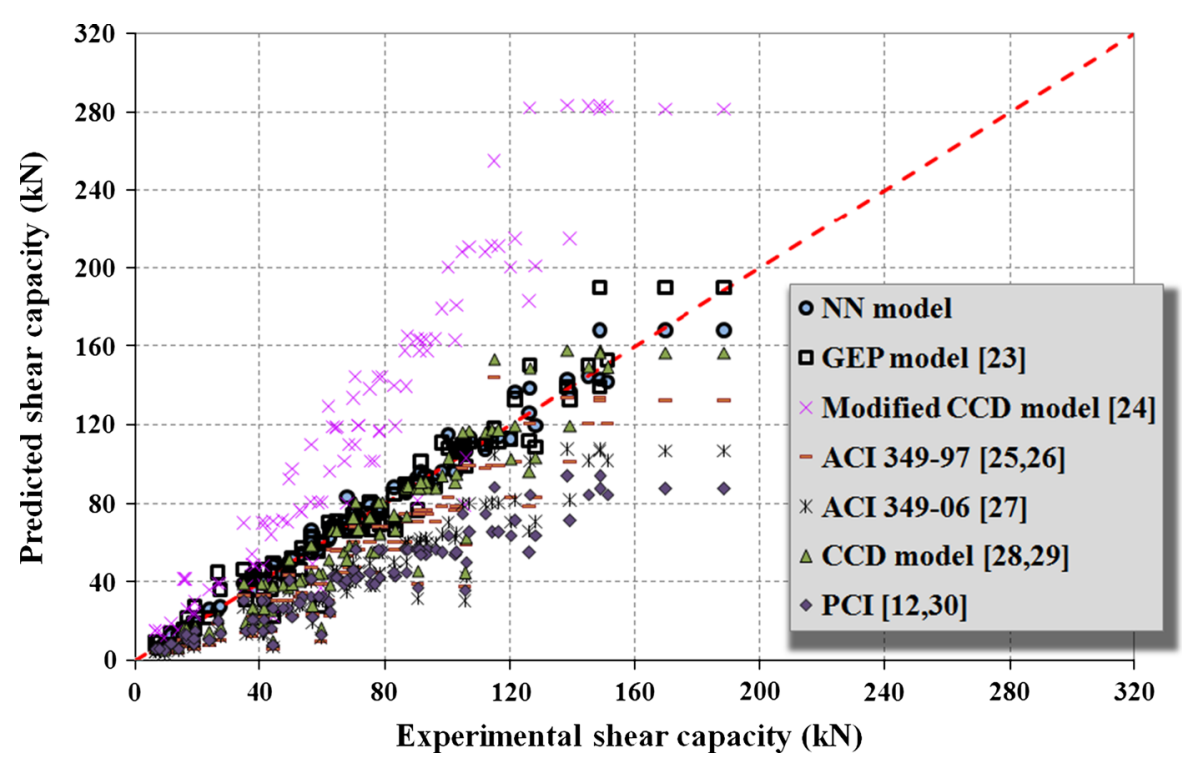

experimental value. The figure also showed that above $30 \mathrm{kN}$ of actual shear value almost all of the predicted values by NN model stayed within $\pm 20 \%$ of the actual values. Of all existing models, GEP model [23] revealed the best performance when compared to the codified models. However, even for this model, significant number of the data seemed to be underestimated and overestimated for the actual shear values of less than $50 \mathrm{kN}$. PCI, ACI 349-97, and ACI 349-06 models demonstrated underestimation performance while Modified CCD model overestimated the shear capacity.

The ranges of the normalized values were $0.76-$ $1.22,0.45-1.69,0.22-1.33,0.50-2.67,0.13-1.22$, 0.15-0.91, and 0.18-0.91 for the NN, GEP, CCD, Modified CCD, ACI 349-97, ACI 349-06, and PCI models, respectively. Although the range of variation is the narrowest for $\mathrm{NN}$ model, it is obvious that only few points had far divergent estimation results. For this reason, in order to assess the performances of the prediction models, the following statistical parameters were calculated and presented in Table 4.
Mean absolute percent error (MAPE)

$$
=\frac{1}{n} \sum_{i=1}^{n}\left|\frac{m_{i}-p_{i}}{m_{i}}\right| \times 100
$$

Mean square error (MSE) $=\frac{\sum_{i=1}^{n}\left(m_{i}-p_{i}\right)^{2}}{n}$,

Root mean square error $(\mathrm{RMSE})=\sqrt{\frac{\sum_{i=1}^{n}\left(m_{i}-p_{i}\right)^{2}}{n}}$,

where $m$ and $p$ are values of measured $\left(m_{i}\right)$ and predicted $\left(p_{i}\right)$ values, respectively.

The critical observation of Table 4 indicated that the lowest errors were found for the proposed NN model. In particular, the lowest MAPE was calculated for the NN model while the highest one was by far observed for Modified CCD model. Although GEP model revealed closest trend to that of proposed NN model, the error values calculated for this model were higher than $\mathrm{NN}$ model. 


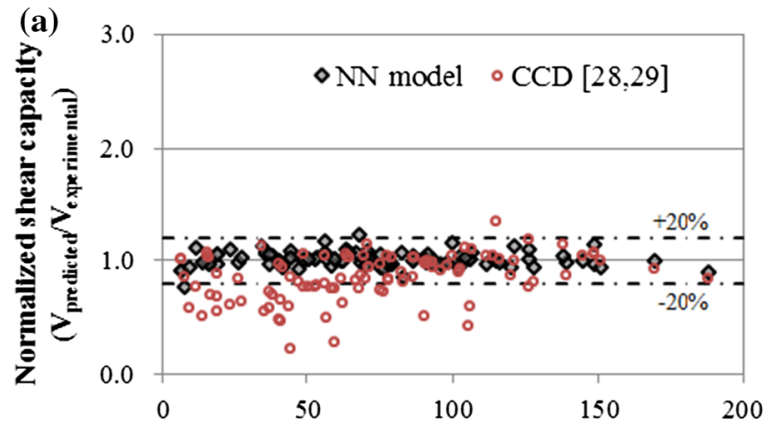

Experimental shear capacity $(\mathrm{kN})$

(c)
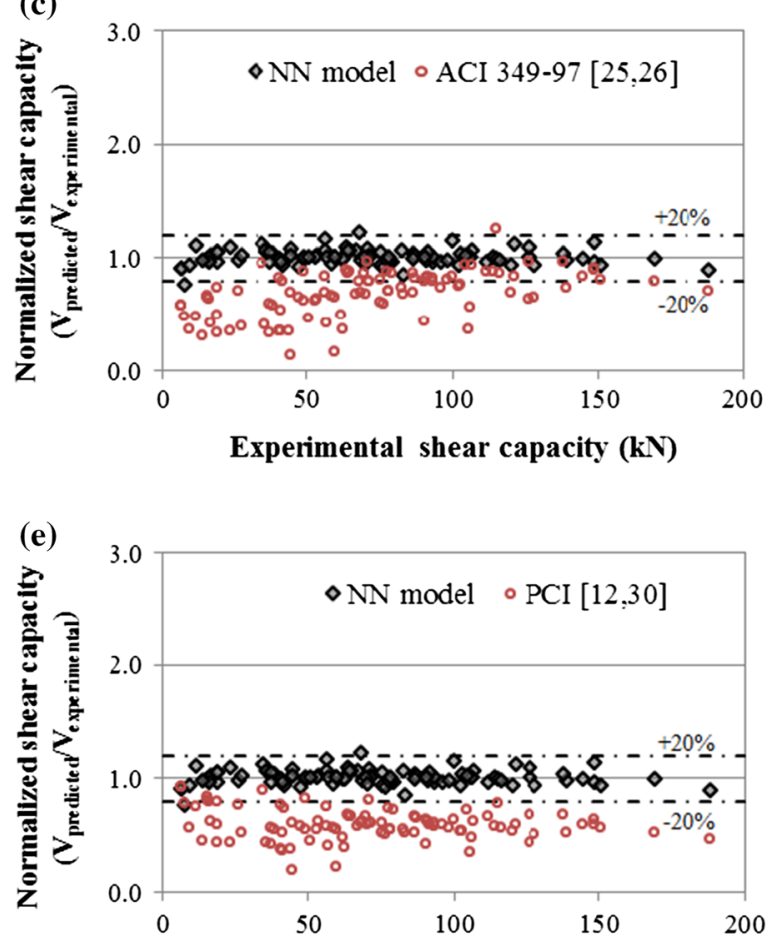

Experimental shear capacity $(\mathrm{kN})$

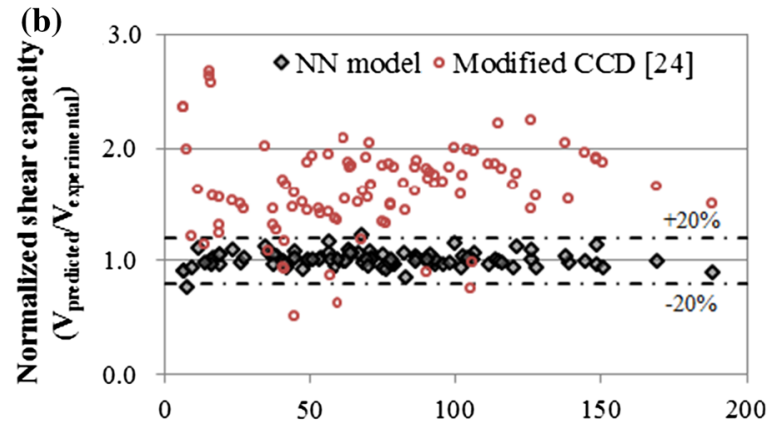

Experimental shear capacity $(\mathrm{kN})$

(d)
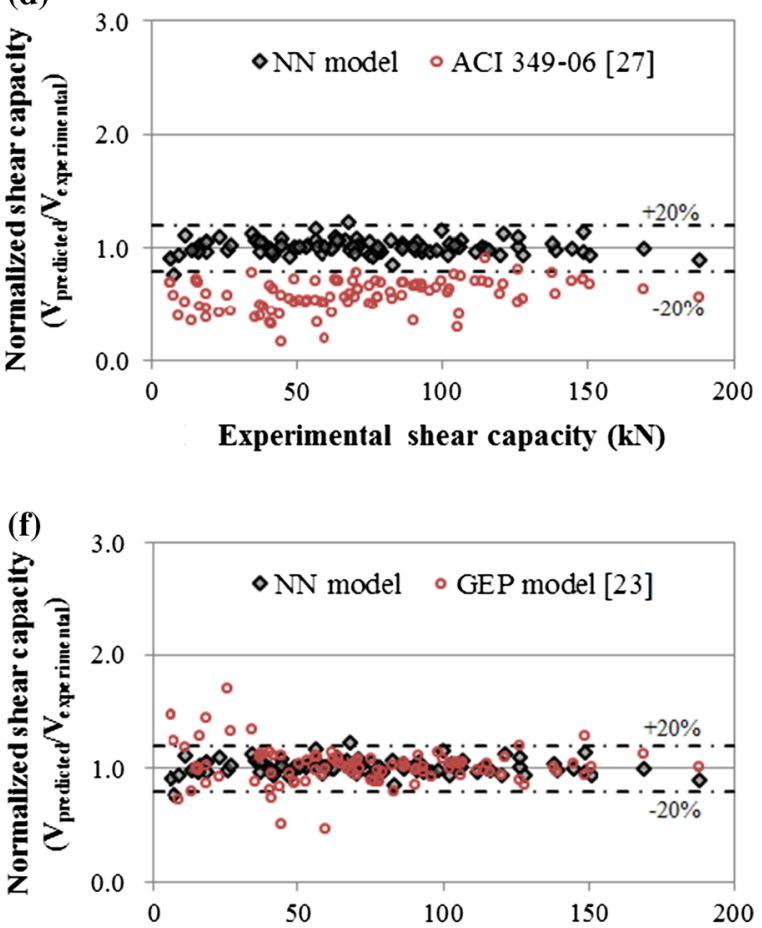

Experimental shear capacity $(\mathbf{k N})$

Fig. 6 Comparing prediction performance of the proposed NN model versus a CCD [28, 29], b modified CCD [24], c ACI 349-97 [25, 26], d ACI 349-06 [27], e PCI models [12, 30], and f GEP model [23]

Table 4 Statistical parameters of the proposed and existing models

\begin{tabular}{|c|c|c|c|c|c|c|c|c|c|}
\hline \multirow[t]{2}{*}{ Parameters } & \multicolumn{2}{|c|}{ NN model } & \multicolumn{2}{|c|}{ GEP model [23] } & \multirow{2}{*}{$\begin{array}{l}\text { CCD model } \\
{[28,29]}\end{array}$} & \multirow{2}{*}{$\begin{array}{l}\text { Modified CCD } \\
\text { model [24] }\end{array}$} & \multirow{2}{*}{$\begin{array}{l}\text { ACI } 349-97 \\
{[25,26]}\end{array}$} & \multirow{2}{*}{$\begin{array}{l}\text { ACI } \\
349-06 \\
{[27]}\end{array}$} & \multirow{2}{*}{$\begin{array}{l}\text { PCI model } \\
{[12,30]}\end{array}$} \\
\hline & $\begin{array}{l}\text { Training } \\
\text { data set }\end{array}$ & $\begin{array}{l}\text { Testing } \\
\text { data set }\end{array}$ & $\begin{array}{l}\text { Training } \\
\text { data set }\end{array}$ & $\begin{array}{l}\text { Testing } \\
\text { data set }\end{array}$ & & & & & \\
\hline MSE & 27.8 & 27.3 & 36.9 & 168.7 & 261.3 & 3858.9 & 556.7 & 1051.5 & 1327.6 \\
\hline MAPE & 4.8 & 4.5 & 10.0 & 14.2 & 18.9 & 66.0 & 33.0 & 42.2 & 41.5 \\
\hline RMSE & 5.3 & 5.2 & 6.1 & 13.0 & 16.2 & 62.1 & 23.6 & 32.4 & 36.4 \\
\hline $\mathrm{R}^{2}$ & 0.983 & 0.984 & 0.977 & 0.918 & 0.883 & 0.885 & 0.866 & 0.883 & 0.886 \\
\hline
\end{tabular}




\section{Conclusions}

The novelty of the current study is due to the explicit formulation of the neural network model to predict the shear capacity of post installed chemical anchors. The presented mathematical relation, when transformed by a computational tool, can be used to control the experimental findings of the researchers and/or to contribute the design procedure adopted by the practitioners in the field. Based on the comparative study presented herein, the following conclusions may be drawn:

- Artificial neural network was proved to be a handful tool with high accuracy of estimation capability of shear capacity of single adhesive anchor post-installed in concrete. Due to low number of nodes and one hidden layer used in the explicit formulation, the model presented here seemed to be more convenient to be used as a prediction model when compared to the most of the NN models given in the literature for engineering problems.

- The number of the experimental parameters used for predicting shear capacity of adhesive anchors was much more than that of the codified models. This may be attributed as the main reason for good prediction performance of the proposed model.

- Although the database used as testing data were not utilized for training, a high level of estimation was acquired for both training and testing data sets associated with low mean absolute percentage of error and high coefficients of correlation. This may be considered as a proof for the generalization capability of the developed model.

- The comparison of the proposed model with the existing formulas available in ACI 349-97, ACI 349-06, ACI 318-08 (CCD method), and PCI-98 design handbook as well as the model proposed by Hoffman, namely, modified CCD method as well as previously presented GEP model indicated that the proposed NN model had relatively better performance, especially for higher shear capacity values than $30 \mathrm{kN}$. The closest prediction tendency to the $\mathrm{NN}$ model was demonstrated by the CCD method.

- Statistical analysis of the results revealed that the lowest errors were observed for the proposed NN model. While the mean absolute percentage of error (MAPE) of the existing models ranged between 10 and $66 \%$, the MAPE of the developed model was about $4.8 \%$ for the training data set and $4.5 \%$ for the testing data set.

Acknowledgments The authors would like to thank to Professor Ashour for providing the database of adhesive anchors. Professor Cook maintains this database on behalf of the ACI Committee 355.

\section{References}

1. Kim JS, Jung WY, Kwon MH, Ju BS (2013) Performance evaluation of the post-installed anchor for sign structure in South Korea. Constr Build Mater 44:496-506

2. Eligehausen R, Cook RA, Appl J (2006) Behavior and design of adhesive bonded anchors. ACI Struct J 103(6):822-832

3. McVay MC, Cook RA, Krishnamurthy K (1996) Pullout simulation of post-installed chemically bonded anchors. J Struct Eng 122(9):1016-1024

4. Cook RA, Kunz J, Fuchs W, Konz RC (1998) Behavior and design of single adhesive anchors under tensile load in uncracked concrete. ACI Struct J 95(1):9-26

5. Cook RA, Konz RC (2001) Factors influencing bond strength of adhesive anchors. ACI Struct J 98(1):76-86

6. Cook RA (1993) Behavior of chemically bonded anchors. J Struct Eng 119(9):2744-2762

7. Gesoğlu M, Özturan T, Özel M, Güneyisi E (2005) Tensile behavior of post-installed anchors in plain and steel fiber reinforced normal-and high-strength concretes. ACI Struct J 102(2):224-231

8. Cook RA, Doerr GT, Klingner RE (1993) Bond stress model for design of adhesive anchors. ACI Struct J 90(5):514-524

9. Higgins CC, Klingner RE (1998) Effects of environmental exposure on the performance of cast-in-place and retrofit anchors in concrete. ACI Struct J 95(5):506-517

10. Fujikake K, Nakayama J, Sato H, Mindess S, Ishibashi T (2003) Chemically bonded anchors subjected to rapid pullout loading. ACI Mater J 100(3):246-252

11. Lee NH, Park KR, Suh YP (2010) Shear behavior of headed anchors with large diameters and deep embedments. ACI Struct J 107(2):146-156

12. Bickel TS, Shaik FA (2002) Shear strength of adhesive anchors. PCI J 47:92-102

13. Xu C, Heping C, Bin L, Fangfang Z (2011) Modeling of anchor bolt pullout in concrete based on a heterogeneous assumption. Nucl Eng Des 241:1345-1351

14. Farrokhzad F, Choobbasti AJ, Barari A (2012) Liquefaction microzonation of Babol city using artificial neural network. J King Saud Univ 24:89-100

15. Llave YA, Hagiwara T, Sakiyama T (2012) Artificial neural network model for prediction of cold spot temperature in retort sterilization of starch-based foods. J. Food Eng 109:553-560

16. Gholizadeh S, Pirmoz A, Attarnejad R (2011) Assessment of load carrying capacity of castellated steel beams by neural networks. J Constr Steel Res 67:770-779 
17. Fonseca RW, Didoné EL, Pereira FOR (2013) Using artificial neural networks to predict the impact of daylighting on building final electric energy requirements. Energy Build 61:31-38

18. Mermerdaş K, Güneyisi E, Gesoğlu M, Özturan T (2013) Experimental evaluation and modeling of drying shrinkage behavior of metakaolin and calcined kaolin blended concretes. Constr Build Mater 43:337-347

19. Ji T, Lin T, Lin X (2006) A concrete mix proportion design algorithm based on artificial neural networks. Cem Concr Res 36:1399-1408

20. Sakla SSS, Ashour AF (2005) Prediction of tensile capacity of single adhesive anchors using neural networks. Comput Struct 83:1792-1803

21. Gesoğlu M, Güneyisi E (2007) Prediction of load-carrying capacity of adhesive anchors by soft computing techniques. Mater Struct 40:939-951

22. Alqedra MA, Ashour AF (2005) Prediction of shear capacity of single anchors located near a concrete edge using neural networks. Comput Struct 83(28-30):2495-2502

23. Gesoğlu M, Güneyisi EM, Güneyisi E, Yılmaz ME, Mermerdaş K (2014) Modeling and analysis of the shear capacity of adhesive anchors post-installed into uncracked concrete. Compos Part B 60:716-724

24. Hofmann J (2004) Tragverhalten und Bemessung von Befestigungen am Bauteilrand unter Querlasten mit beliebigem Winkel zur Bauteilkante (Load- Bearing Behaviour and Design of Fasteners Close to an Edge under Shear Loading with an Arbitrary Angle to the Edge), $\mathrm{PhD}$ thesis, Institut für Werkstoffe im Bauwesen, Universität Stuttgart (in German)
25. Ueda T, Kitipornchai S, Ling K (1990) Experimental investigation of anchor bolts under shear. J Struct Eng 116(910-92): 1

26. ACI Committee 349 (1997) Code requirements for nuclear safety-related concrete structures and commentary (ACI 349-97). American Concrete Institute, Farmington Hills

27. ACI Committee 349 (2007) Code requirements for nuclear safety-related concrete structures and commentary (ACI 349-06). American Concrete Institute, Farmington Hills

28. ACI Committee 318 (2008) Building code requirements for structural concrete (ACI 318-05) and commentary (318R08). American Concrete Institute, Farmington Hills

29. Fuchs W, Eligehausen R, Breen JE (1995) Concrete capacity design (CCD) approach for fastening to concrete. ACI Struct J 92:73-94

30. PCI Design Handbook (1998) Precast-prestressed concrete, 5th edn. Precast-Prestressed Concrete Institute, Chicago

31. Zadeh LA (1994) Soft computing and fuzzy logic. IEEE Softw 11(6):48-56

32. Gao S, Zhang Z, Cao C (2011) Road traffic freight volume forecast using support vector machine combining forecasting. J Softw 6:1680

33. Schalkoff RJ (1997) Artificial neural networks. McGrawHill, Columbus

34. Haykin S (2000) Neural networks: a comprehensive foundation. Macmillan College Publications Cooperation, New York

35. Hebb DO (1949) The organization of behavior. Wiley, New York

36. Sušac MZ, Šarlija N, Benšić M (2005) Selecting neural network architecture for investment profitability predictions. J Inf Org Sci 29(2):83-95 